\title{
Position statement on the specialist old age psychiatry team and nursing/residential care home residents. Good practice principles and potential practice development
}

\section{Purpose of the statement}

This position statement has been produced by the Faculty for the Psychiatry of Old Age to address some principles of good practice, and potential practice development, by specialist old age psychiatry teams, in relation to nursing/ residential care homes, in the context of concerns about such care provision for those with mental health needs.

\section{Background}

In 1994, there were reported to be around 148500 beds in private and voluntary nursing homes (and hospitals), and around 210100 independent sector residential homes places (together with around 69000 Part III homes places) in England and Wales, trends also evident in the rest of the UK - important context for new guidance issued on continuing health care needs (Department of Health, 1994, 1995). While partially reflecting growth in the elderly population needing care, this also represents a major shift into primary care of large numbers who previously would have received specialist secondary care - many with complex, multiple care needs, both mental and physical.

The literature detailing the significant mental health problems of a substantial proportion of those in homes is now large and well-known. Better outcomes should be achieved when problems are addressed earlier rather than later. This means very large numbers whose care needs may be being inadequately addressed, a major challenge for nursing/residential care purchasers and providers, and a considerable new task for primary health care teams (PHCTs).

For specialist old age psychiatry teams (specialist teams), there can be problems of variability in the level, quality and expertise of such provision. From a national perspective, for residents and families, there remains potential for inconsistency in standards and inconsistency in eligibility criteria for NHS or social service funding between different districts.

Supporting the PHCT with the provision of general medical services to such residents seems a central pillar of maintaining good quality care. Good care provision should be greatly aided by effective collaboration and liaison partnerships between specialist teams, social services and
PHCTs. Good assessment (Royal College of Psychiatrists, 1996) of and planning for future care needs around the time of entry to care, employing specialist team expertise, as appropriate, are important. Specialist teams, particularly, have an established role and expertise in continuing care provision for those with mental health needs, which could be beneficial in providing training, advice and support to the nursing/residential homes sector.

\section{Summary of good practice and potential practice development}

(a) Specialist teams should assist PHCTs in maintaining good quality general medical care and support to homes residents with particular mental health care needs.

(b) Specialist teams should be available to assist good needs assessment around entry into homes, to enable future care planning and to promote necessary continuity in continuing care.

(c) Specialist teams should seek good collaborative liaisons with PCHTs and social services (and with geriatric medicine) to aid good quality care provision in homes.

(d) Specialist teams should promote continuity of care for those who particularly need this and continuity of relationships with those providing such care.

(e) In contacts with care homes, specialist teams should promote the importance of:

(i) approaches to prevention of disability:

(ii) maintenance of function and a stimulating environment;

(iii) an ethos of rehabilitation;

(iv) the need to minimise unnecessary medication, especially that which may impair alertness or cognitive function;

(v) respect for individuality and autonomy despite mental impairment;

(vi) the detection of and therapeutic potential in, particularly, delirium, depression and remediable aspects of dementia.

(f) Specialist teams should aid continuity of care through their availability for re-referral 
and ensuring clarity over re-referral arrangements.

(g) Specialist teams can promote liaison relationships with PHCTs through the use of community psychiatric nurses (or other team members) and, similarly, liaison relationships with particular homes.

(h) Specialist teams could advise PHCTs on devising protocols in collaboration with homes' teams, to deal with common problems and good care delivery.

(i) Specialist teams could advise PHCTs and homes with joint audit work on good care.

(j) Specialist teams could maximally exploit educational opportunities arising in their contacts with homes and PHCTs, and be available for education and training programmes.

(k) Specialist teams could be available to advise purchasers and regulatory authorities concerning provision of care by homes.

(l) Opportunities to implement such principles of good practice will be influenced strongly by resource provision.

\section{Conclusion}

A major challenge for appropriate care provision, and support of primary care, now exists in this area. A collaborative approach between specialist old age psychiatry teams and the partners involved with nursing/residential care homes, especially with primary care, should be employed and is likely to lead to better care delivery. Useful principles of good practice (and for improving practice), from the specialist team perspective, have been briefly stated, though their delivery will be likely to vary with local resource provision and organisational arrangements.

\section{References}

DEPARTMENT OF HEALTH (1994) Guidance to Health Authorities on Clarifying Responsibilities for Long Term Care, HSG/(94)56. London: Department of Health.

- (1995) NHS Responsibilities for Meeting Continuing Health Care Needs, HSG(95)8. London: Department of Health.

Royal College of Psychiatrists (1996) Consensus Statement on the Assessment and Investigation of an Elderly Person with Suspected Cognitive Impairment by a Specialist Old Age Psychiatry Service, Council Report CR49. London: Royal College of Psychiatrists.

Produced by Dr Rob Jones on behalf of the Psychiatry of Old Age Faculty. Approved by Council, January 1998.

\begin{tabular}{|c|c|c|}
\hline \multicolumn{3}{|c|}{$\begin{array}{l}\text { The Royal College of Psychiatrists, } \\
\text { in Association with Sections of Forensic Psychiatry and CPS at Sheffield University, Rampton Hospital } \\
\text { Authority and Rotherham Priority Health NHS Trust }\end{array}$} \\
\hline \multicolumn{3}{|c|}{$\begin{array}{c}\text { CONFIDENTIALITY - } \\
\text { "WHO TO TELL WHAT TO, WHEN, AND WHY" }\end{array}$} \\
\hline \multicolumn{3}{|c|}{$\begin{array}{l}\text { This conference aims to address the concept of confidentiality both from a general and a specifically psychiatric } \\
\text { pespective in the context of rapidly changing expectations, practice, guidelines, and statute and case law. }\end{array}$} \\
\hline \multicolumn{3}{|c|}{$\begin{array}{l}\text { Over the one and a half days there will be eleven presentations by invited speakers as well as ample opportunity for small } \\
\text { group and plenary discussions. }\end{array}$} \\
\hline \multicolumn{3}{|c|}{$\begin{array}{l}\text { This meeting is especially timely as the GMC is in the process of re-issuing its guidelines on 'Confidentiality: providing } \\
\text { and protecting information', and the Royal College of Psychiatrists' working party is about to circulate its own draf } \\
\text { proposals on confidentiality. It will provide a forum to take stock of the present status of professional confidentiality, to } \\
\text { share contemporary difficulties and to encourage discussion of the particular dilemmas which arise in our different sub- } \\
\text { specialities and roles. }\end{array}$} \\
\hline \multicolumn{3}{|l|}{ Speakers so far include: } \\
\hline Dr Susan Bailey & Dr Susan Benbow & Mr Christopher Bollas (Psychoanalyst) \\
\hline Dame Fiona Caldicott & Professor Christopher Cordess & Professor Bill Fulford \\
\hline Professor Raanan Gillon (Ethics) & Mr Anthony Harbour (Solicitor) & Mr Alan Levy QC \\
\hline Mr Neil Marshall (GMC) & Professor Roy McClelland & Dr Judith Trowell \\
\hline \multicolumn{3}{|c|}{ The programme includes time for small group discussion as well as plenary sessions. } \\
\hline & In & \\
\hline
\end{tabular}

